\title{
Accumulation of Urea and Allantoin during Purine Utilization by Germinating Spores of Geotrichum candidum
}

\author{
By I. BARASH \\ Department of Botany, Tel Aviv University, Tel Aviv, Israel
}

(Received 6 March 1972; revised 27 April 1972)

\begin{abstract}
SUMMAR Y
Urea and allantoin were accumulated by germinating spores of Geotrichum candidum in the presence of xanthine, uric acid or allantoin. The concentration of endogenous allantoin was 5 to Io times higher than that of urea. The specific activities of uricase and allantoicase were increased about nine- and fivefold respectively by uric acid and allantoin. No induction of allantoinase and ureidoglycolase was detected. Results may suggest that the different levels of purine degradative enzyme during induction might favour allantoin accumulation and prevent urea from attaining a toxic concentration.
\end{abstract}

\section{INTRODUCTION}

It has been shown (Shorer, Zelmanowicz \& Barash, 1972) that the accumulation of urea in spores of Geotrichum candidum inhibits protein synthesis and germination. Spores of G. candidum lack urease, yet urea is readily metabolized by an ATP-dependent urea amidolyase to $\mathrm{CO}_{2}$ and $\mathrm{NH}_{3}$ (Shorer et al. 1972). Since urea is deleterious to the germination process, it is of interest to know the potential capability of the spores to prevent the accumulation of metabolically formed urea. Urea can be produced by the arginase reaction in which arginine is hydrolysed to ornithine and urea (Srb \& Horowitz, I944). The only other major source of urea in fungi is the degradation of purines (Scazzocchio \& Darlington, 1968). The present communication describes the effect of purine utilization by the spores on the endogenous levels of urea and allantoin.

\section{METHODS}

Spores of Geotrichum candidum were obtained as described previously (Barash, I968). The spores were incubated with various substrates (see Fig. I), and then extracted with boiling distilled water as described by Shorer et al. (1972). The extract was used for the colorimetric determination of endogenous urea (Shorer et al. 1972) and allantoin (Trijbels \& Vogels, I966) as well as for the detection of purine intermediates by paper chromatography (Amman \& Lynch, 1964) by means of $n$-butanol-acetic acid-water (I00:22:50).

For the determination of enzyme activities the spores were disrupted with a cooled Aminco French Pressure cell in 50 mM-tris- $\mathrm{HCl}$ buffer, $\mathrm{pH} 8$. The crude extract was centrifuged at $27,000 \mathrm{~g}$ for $10 \mathrm{~min}$ and the supernatant fluid was dialysed against the same buffer for $\mathrm{I} 6 \mathrm{~h}$ at $4{ }^{\circ} \mathrm{C}$. Uricase (urate: $\mathrm{O}_{2}$ oxidoreductase, EC. $\mathrm{I}$. 7.3.3) was assayed by measuring the rate of disappearance of uric acid (Scazzocchio \& Darlington, 1968). The assay mixture contained $200 \mathrm{~mm}$-borate buffer, $\mathrm{pH} 8 \cdot 3,0.2 \mathrm{~mm}$-uric acid and $0.2 \mathrm{ml}$ of crude extract to a final volume of $3 \mathrm{ml}$. Allantoinase (allantoin amidinohydrolase, EC. 3.5.2.5) was assayed according to Singh, Angelo \& Neucere (1970). The assay of allantoicase (allantoate amidino- 


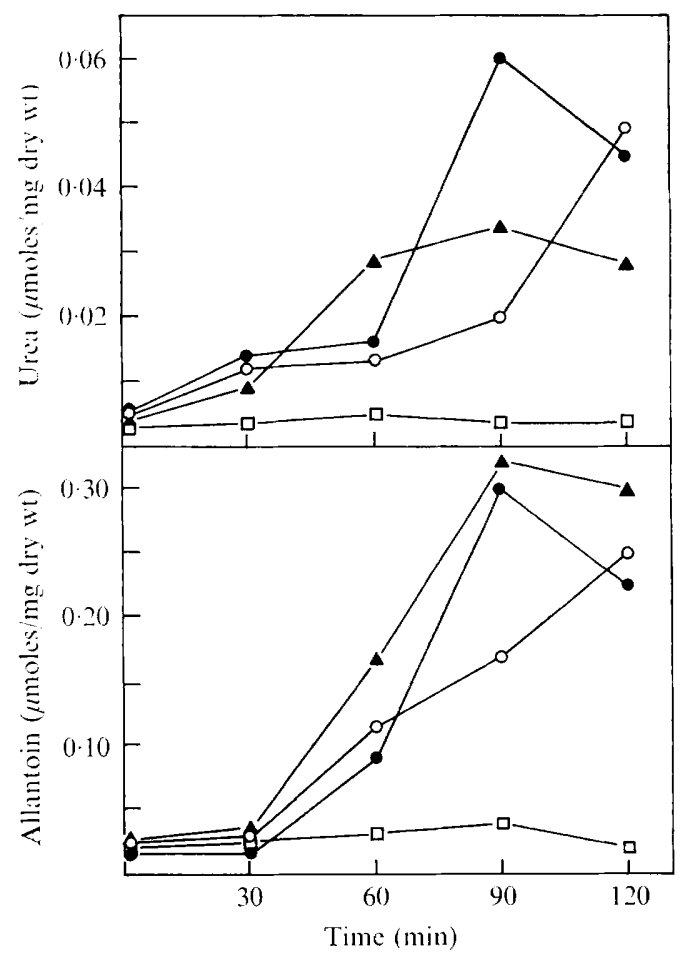

Fig. I. The accumulation of endogenous urea and allantoin in germinating spores during utilization of purine breakdown intermediates. Spores $(0.5 \mathrm{mg} / \mathrm{ml})$ were preincubated for $2 \mathrm{~h}$ in $0.5 \%$ glucose solution at $30^{\circ}$ on a reciprocal shaker before addition of the following intermediates at a final concentration of $10^{-3} \mathrm{M}$ : xanthine (O); uric acid (A); allantoin (O); control $(\square)$.

hydrolase, EC. $3 \cdot 5 \cdot 3 \cdot 4$ ) was based on the method of Trijbels \& Vogels (I966). The reaction mixture contained $\mathrm{I} \mathrm{mg}$ potassium allantoate, $200 \mathrm{~mm}$ tris- $\mathrm{HCl}$ buffer, $\mathrm{pH} 7$, and $0.3 \mathrm{ml}$ crude extract to a final volume of $3 \mathrm{ml}$. Incubation was carried out at $30^{\circ} \mathrm{C}$ for $30 \mathrm{~min}$. Ureidoglycolase was determined according to Gaudy, Bojanowski, Valentine \& Wolfe (I965). One unit for each of these enzymes was defined as the amount of enzyme required for the formation of I nmole of product per min under the assay conditions used.

\section{RESULTS AND DISCUSSION}

When xanthine, uric acid or allantoin were added to germinating spores, endogenous urea accumulated (Fig. I). However, even the maximum level of intracellular urea (0.06 $\mu \mathrm{mol} / \mathrm{mg}$ spores) was lower than the toxic concentration required to inhibit spore germination (Shorer et al. 1972). The amount of urea formed from purine breakdown might be controlled either by the activities of enzymes leading to urea formation or to the removal of urea. Fungi have been found to degrade purines by the well-known aerobic pathway (Scazzocchio \& Darlington, I968):

hypoxanthine $\rightarrow$ (xanthine) $\rightarrow$ uric acid $\rightarrow$ allantoin $\rightarrow$ allantoic acid $\rightarrow$

$$
\text { ureidoglycolate }+ \text { urea } \rightarrow \text { glyoxylate }+2 \text { urea. }
$$

The possibility that the accumulation of any of the latter intermediates might slow down the formation of urea was therefore investigated. Concentrates of extracts were prepared from spores incubated for $2 \mathrm{~h}$ under conditions described in Fig. I. Analysis of these extracts by 
Table I. The effect of various intermediates on levels of enzymes involved in purine catabolism*

\author{
Intermediate \\ (I $\mathrm{mm}$ )
}

Xanthine

Uric acid

Allantoin

K-allantoate

Ureidoglycolate

Urea

Glutamine

Glutamine

\section{Enzyme level (units/mg protein) $\dagger$}

\begin{tabular}{cccc}
\hline \multicolumn{4}{c}{ Enzyme level (units/mg protein) $\dagger$} \\
Uricase & Allantoinase & Allantoicase & Ureidoglycolase \\
206 & 20 & 19 & 90 \\
220 & 30 & 32 & 163 \\
24 & 28 & 22 & 89 \\
25 & 23 & 4 & 76 \\
25 & 31 & 4 & 117 \\
23 & 22 & - & 90 \\
25 & 23 & - & 95 \\
21 & 22 & 4 & 95
\end{tabular}

* Germination conditions were as described in Fig. I. Enzymes were assayed $2 \mathrm{~h}$ after the addition of the intermediates to the glucose $(0.5 \%)$ medium. Germination rate was similar in all treatments.

$\dagger$ Specific activities were an average of at least three different experiments.

paper chromatography showed that allantoin was the only compound which produced a well defined coloured spot. All other intermediates could hardly be detected on the chromatogram. The increase in allantoin concentration during germination was followed quantitatively by the differential procedure of Trijbels \& Vogels (1966). The maximum amount of endogenous allantoin from the various purine intermediates was 5 to Io times higher than urea under the same conditions (Fig. I). In contrast to its behaviour in Chlorella pyrenoidosa (Amman \& Lynch, 1964), allantoin could be transported into the germinating spores, and the accumulation of allantoin under the conditions used was not toxic although it has been reported to be so for Asperillus (Darlington \& Scazzocchio, 1967). Allantoin has been found to play an important role in the storage and translocation of nitrogen in some plants (Reinbothe \& Mothes, I962) and might have a similar function in Geotrichum candidum.

The effect of purine intermediates on enzyme levels of the uricolytic pathway is given in Table I. Uricase and allantoicase were increased about 9 and 5 times respectively by uric acid and allantoin. Allantoinase and ureidoglycolase showed no marked induction although the former enzyme was inducible in Aspergillus (Scazzocchio \& Darlington, 1968). It is noteworthy that the specific activity of uricase under inductive conditions was approximately sevenfold higher than that of allantoinase (Table I). Although more information on the kinetics of the enzymes involved in purine degradation is required in order to determine the conversion rate of each substrate, the different levels of uricase and allantoinase might be responsible for allantoin accumulation. The differential induction may be one of the mechanisms which prevents urea from attaining toxic levels.

\section{REFERENCES}

Amman, E. C. B. \& Lynch, V. H. (1964). Purine metabolism by unicellular algae. II. Adenine, hypoxanthine and xanthine degradation by Chlorella pyrenoidosa. Biochimica et biophysica acta 87, 370-379.

BARASH, I. (1968). Liberation of polygalacturonase during spore germination by Geotrichum candidum. Phytopathology 58, I364-I37I.

Darlington, A. J., Scazzocchio, C. (1967). Use of analogues and the substrate-sensitivity of mutants in analysis of purine uptake and breakdown in Aspergillus nidulans. Journal of Bacteriology 93, 937-940.

Gaudy, E. T., Bojanowski, R., Valentine, R. C. \& Wolfe, R. S. (1965). Ureidoglycolate synthetase of Streptococcus allantoicus. I. Measurement of glyoxylate and enzyme purification. Journal of Bacterio$\log y 90,1525-1530$. 
Reinbote, H. \& Mothes, K. (1962). Urea, ureids and guanidines in plants. Annual Review of Plant Physiology 13, I 29-150.

Scazzocchio, C. \& Darlington, A. J. (1968). The induction and repression of the enzymes of purine breakdown in Aspergillus nidulans. Biochimica et biophysica acta 166, 557-568.

SHORER, J., ZELMANOWICZ, I. \& BARASH, I. (I972). Utilization and metabolism of urea during spore germination by Geotrichum candidum. Phytochemistry II, 595-605.

Singh, R., Angelo, A. J. \& Neucere, N. J. (1970). Unusual heat stability of peanut allantoinase. Phytochemistry 9, I535-1538.

SRB, A. M. \& HoROWITZ, N. H. (1944). The ornithine cycle in Neurospora and its genetic control. Journal of Biological Chemistry 154, I29-139.

TriJBels, F. \& Vogels, G. D., (1966). Degradation of allantoin in Pseudomonas acidovorans. Biochimica et biophysica acta 113, 292--301. 